\title{
The case for fortified flour
}

\section{By D. W. Kent-Jones, The Laboratories, Dudden Hill Lane,}

\author{
Willesden, London, N.W. 1
}

In presenting the case for fortified flour I have purposely tried to avoid argument and to deal with established facts. I must, however, recall the strong preference of the public for white bread as against even the slightly darker bread made from $80 \%$ extraction flour. I can, of course, give, and on other occasions have given, proof of it, but I am assuming that it is accepted by this Society, even if some members deplore the fact. Of course, it is only because the public, if given a chance, will not eat bread darker than that made from what is commonly called white flour that the question of fortification has arisen. We know and all agree that low levels of thiamine, nicotinic acid, iron and calcium can be easily corrected by enrichment or fortification, but what remains in doubt to some is whether as a result other components of the B complex or some other important nutrient factor may be absent from the diet, if bread made from fortified white flour is consumed as opposed to darker bread made from flour of $80 \%$ or $85 \%$ extraction.

The respective merits of bread made from long-extraction flour and of bread made from white flour enriched with certain addenda such as synthetic thiamine, nicotinic acid and with iron and creta praeparata has already been thrashed out by what is called the Cohen Committee (Great Britain. Parliament, I956), who had the benefit of hearing expert evidence from those favouring the one view and those who gave their reasons for preferring the other view. With such a full inquiry, there seems little point in a polemic discussion on the matter. All I am asked to do is to restate the case for the fortification of white flour, but at least I will be allowed to point out that I have already given this Society a paper on this very subject entitled Enrichment (Kent-Jones, 1946).

In that paper I reviewed no less than I I years ago the position as we then understood it and I find little to add or to change. The crux of the matter is whether the population eating, in its normal mixed diet, bread made from fortified or enriched white flour, as against bread from longer-extraction flour, will suffer any defect or consume less of any nutrient factor so that its health or well-being is affected.

One point might be borne in mind. There is, of course, destruction of certain nutrients in cooking and baking. In this paper I have only considered bread, but only about $65 \%$ of the total flour manufactured is used for the production of bread. Some $35 \%$ of the flour production is utilized in the making of cakes, biscuits, homecooking, and so on. In some of these instances the rate of destruction of thiamine, for example, may be different from that which occurs in ordinary yeast fermentation and bread baking. Much will depend on the $\mathrm{pH}$ of the goods at the time of the baking or cooking. The point may not be serious but it is one that should be remembered. 


\section{Fortification}

Fortification, or enrichment of flour, has, of course, been carried out in the United States and elsewhere for many years and for hundreds of millions of people. In this country we still think of fortification or enrichment in the terms of what flour should contain if what were described as 'token nutrients' by the Conference on the Post-War Loaf (Great Britain. Parliament, 1945) are present, per $100 \mathrm{~g}$ flour: $0.24 \mathrm{mg}$ thiamine, $\mathrm{r} \cdot 60 \mathrm{mg}$ nicotinic acid and $\mathrm{r} .65 \mathrm{mg}$ iron. In fact, the Conference on the Post-War Loaf posed certain queries and the first and main one was: "How low extraction flour suitably reinforced with the "token" nutrients compares from a nutritional point of view with high extraction flour obtained wholly from the wheat grain.'

To answer this question, the famous experiment was especially designed and most carefully carried out on children in German orphanages and fully reported upon by Widdowson \& McCance (1954). I take it that all are conversant with this report, but I must make some reference to it later. It will be remembered that the results were startling and unexpected. All the children throve extraordinarily well, whether the bread they consumed was made from unenriched white flour, enriched white flour, $85 \%$ flour or wholemeal. However, the levels of fortification originally suggested by the Conference on the Post-War Loaf are now under re-examination by the Food Standards Committee of the Ministry of Agriculture, Fisheries and Food, who are considering whether the suggested levels for the thiamine, nicotinic acid and iron are too low and also, amongst other things, if fortification with riboflavin should be carried out.

\section{Recent work}

Since my last paper before this Society we have naturally gained further knowledge. Thus we now have, thanks largely to microbiological assays, more precise ideas as to the quantities of what might be called the minor components of the B group of vitamins in flours of different extractions. I had attempted to survey this position (Kent-Jones, 1949-50) and most of the figures I then suggested have stood the test of the 7 years' interval save those I gave for pantothenic acid, in which I had unduly favoured the longer-extraction flour. Since this is almost the heart of the matter, I have drawn up another table giving what I believe to be the facts as established by recent analyses.

Although an idea has been given as to probable extent of change in the amount of protein, I have not attempted to give figures for calcium and iron since so much depends on 'availability' and in any event there is no real difficulty in fortification with these nutrients. At present fortification with iron and calcium is the settled Government policy.

If we assume that the present-day system of fortification also deals adequately with thiamine and nicotinic acid, the crux of the matter comes in the figures reported for pyridoxine, pantothenic acid, biotin and folic acid.

The change in riboflavin with extraction rate of flour is very much less than with thiamine. The same applies to pyridoxine, and there is still less change with 
Table I. Protein and vitamin composition of flours of different extractions expressed (except as otherwise stated) as $\mathrm{mg} / \mathrm{1} 00 \mathrm{~g}$

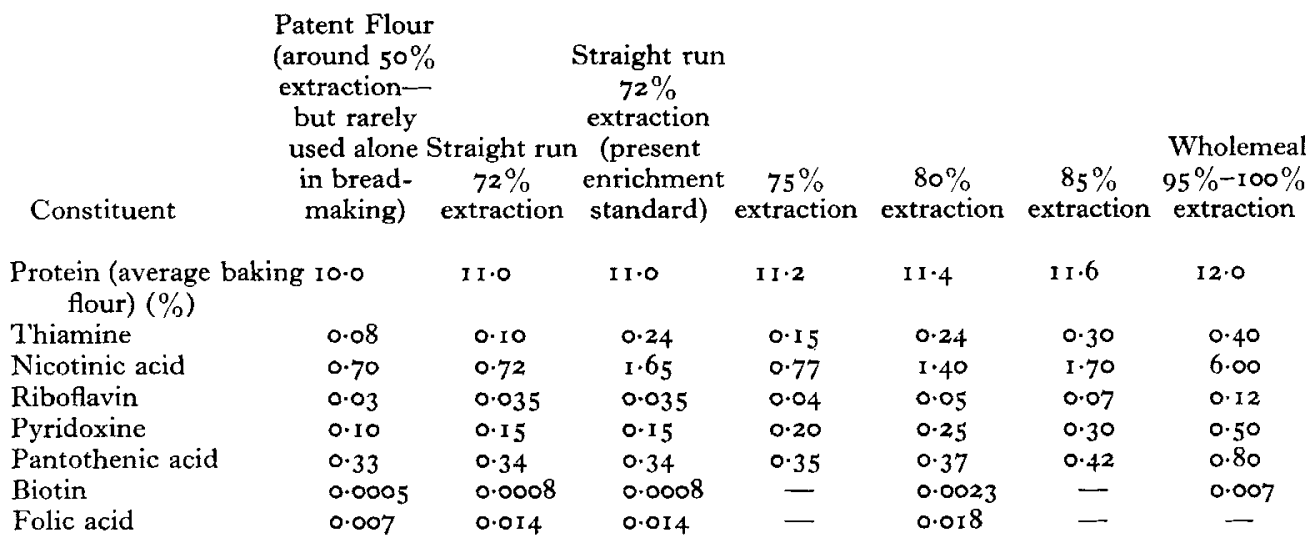

pantothenic acid. The change in folic-acid content between ordinary white flour ( $72 \%$ extraction) and $80 \%$ extraction is remarkably little. There is, however, a more serious change with biotin, but the assays have scarcely the same degree of accuracy, as anyone will know who has worked in this field. In any event, all the figures reported are low and lower-extraction flours are by no means devoid of the rarer components of the B complex.

The direct evidence of the absence or of sufficient amounts of an important necessary nutrient factor is obviously slight as bread is only one component of the diet. It must be stressed that we know little of the actual daily requirements for most of these minor components of the B complex. It is therefore fortunate that a fair amount of indirect evidence exists which supports the belief that the present-day system of flour enrichment does not result in the diet being insufficient in essential nutrients. When I concluded my paper in 1946 I said:

'The only scientific argument which it is perhaps possible to use against the enrichment policy is that, even in the U.S.A., the addition of synthetic vitamins may still result in the exclusion of some essential factors present in longer extraction flour. This may, of course, be so, although it seems unlikely with the comprehensive system of enrichment practised in U.S.A., which could presumably be practised in this country also if thought desirable. It is, of course, almost impossible to combat such an argument. Evidence on the point may, however, be forthcoming. In pre-war days malnutrition was rife in Newfoundland where people were living under severe conditions, and this was doubtlessly due in part to lack from the diet of the $\mathbf{B}$ group of vitamins. In pre-war days also, longer extraction flour was made compulsory and improvement in health soon took place. Newfoundland has now changed to enriched U.S.A. flour. If the improvement in health continues, as is confidently expected that it will, then perhaps it can be safely and fairly agreed that in present day enriched flour no unknown essential factor is missing' (KentJones, I946). 
We now have a clear answer but we are rather inclined to forget this well-conducted and large-scale Newfoundland experiment. The experiment lasted over a period of no less than 4 years and many hundreds of people were submitted to the most careful clinical and other tests by an experienced group of medical men, biochemists and others at the beginning and at the end of the experiment. As a matter of fact over 800 people were examined in 1948 and of these over 300 had been examined in 1944. It is therefore pertinent to quote a review of the work given by Wilder (1949):

'In Newfoundland, however, we have had a demonstration of the value of enrichment which everyone can recognise. Here is an experiment in nutrition with conditions controlled, as demanded by the scientist, yet on a scale large enough to be impressive to the layman. You have seen the data of the surveys of 1944 and I 948 and you have heard that fortification of margarine and enrichment of flour were introduced in Newfoundland in 1944. You have learned that the outward signs of malnutrition had become less conspicuous and less prevalent in 1948 than they were in 1944. Furthermore, with the disappearance of these outward signs of malnutrition had gone much of the apathy and listlessness so characteristic of the population in 1944. The quality of life had improved in Newfoundland. So, too, to judge by such criteria as mortality rates, had the quantity of life. The reported death rate from all causes fell from 12.1 to 10.5 per thousand of the population. The number of deaths from tuberculosis decreased sharply, and the rate of still births and of deaths of infants less than I year of age was strikingly reduced (the average annual infant mortality for the period I 940 to I 944 for the city of St. John's, for which such rates are more reliable than for the country as a whole, was I02.3; the rate for 1947 was 61 0 per thousand live births). A post hoc ergo propter hoc conclusion is, of course, unjustified. Simply because frogs are found on the roof after a rainfall does not mean that it has rained frogs. Other things occurred which may have influenced the nutrition of the population and with it the public health. The people had much more money to spend and could have purchased more or better food. However, the data indicated that this was not the case. They had more money but they did not purchase better food. Not all the outward signs of malnutrition had decreased in prevalence. Only those had lessened which could have been affected by addition of vitamin $A$ to margarine and of riboflavin, niacin and thiamine to the flour. There was no improvement, and indeed, a worsening with respect to the prevalence of lesions relatable to deficiency of vitamin C (ascorbic acid)'.

Surely this is striking evidence of the value of enriched flour in the diet (American enrichment, i.e., per $1 \mathrm{~b} ., 2 \cdot 0-2 \cdot 5 \mathrm{mg}$ thiamine, $\mathrm{I} \cdot 2-\mathrm{r} \cdot 5 \mathrm{mg}$ riboflavin, $16-20 \mathrm{mg}$ nicotinic acid and $13-16.5 \mathrm{mg}$ iron). There was obviously no indication in this reasonably long and widespread test so carefully controlled and conducted that there was any sign of a missing nutrient even though the bread was made from enriched flour and not from long-extraction flour. It is also of interest to note that Wilder (I956) a past Chairman of the Council on Food and Nutrition, in a review of enrichment based on American experience gave wholehearted support. 


\section{Conclusion}

It is true that the Cohen Committee (Great Britain. Parliament, I956), having heard all the facts, were not impressed that any danger resulted from the use of fortified flour as opposed to longer-extraction flour. The matter has already been impartially and critically examined - does it help to do so again. The Committee was opposed to the use of unenriched white flour, but was not impressed with the view that in a mixed diet there was any danger from variation in protein quality in flour of different extraction. In discussing this problem I feel that this is so admirably summed up by the Committee that it is worth while quoting a relevant part:

'Human requirements of pyridoxine, pantothenic acid, biotin and folic acid are not known and information as to their distribution in foods and flours of various grades is far from complete. The Panel's review of the relevant literature leads them to believe that, in spite of weighty opinion to the contrary, a lowering of the extraction rate from 80 per cent. to 70 per cent. is very unlikely to lead to any nutritional disturbance from lack of these vitamins.'

'Bread made from either 80 per cent. extraction or 70 per cent. extraction enriched flour is an excellent food. A true 80 per cent. extraction flour may give a more widely spread insurance against possible, but as yet unproved, deficiency in the rest of the diet; the 70 per cent. enriched flour gives a more certain cover against possible deficiency of the three "token" nutrients with well recognised deficiency states.'

Finally, I do very strongly feel that in this matter there has been too much partisanship for the various points of view by those who have interested themselves in the subject, and of course the fault is not all on one side. I think, however, most of us have been impressed with a recent book reviewing the subject by McCance \& Widdowson (1956). Although there may be some who query the planning of the German experiment with which this book deals in some detail, none will query the actual findings. I cannot help feeling that those who query the general validity of the results of this experiment, planned and especially carried out for the Medical Research Council, to answer the query raised by the Conference on the Post-War Loaf, might do well to reread and restudy Chapter 8 of that book entitled Progress by Experiment. Indeed, the theme of this outstanding and outspoken book is 'Why think-why not try the experiment'. The authors were just as critical of themselves as they were of others on both sides in this matter and stated:

'We came to the conclusion that our ideas had been wrong and we have set down our reasons for thinking so. The reader will also find a summary of the experimental test that did not give the results we had anticipated, and the steps we took to check it by further work.'

It may be stated that the famous test in the German orphanage showed that unenriched flour was as good as flour enriched with the token nutrients (per $100 \mathrm{~g}$ flour: thiamine $0.24 \mathrm{mg}$, nicotinic acid $\mathrm{I} \cdot 60 \mathrm{mg}$, iron $\mathrm{I} \cdot 65 \mathrm{mg}$ ) and this is not perhaps the time to discuss this aspect of the problem. The explanation of this. apparent paradox was quite clearly put forward by me to the Cohen Committee and concerns the nature of the unenriched $70 \%$ white flour used and a study of the thiamine in 
the urinary excretions. It may also be argued that when fortified white bread is used in the diet there may be insufficient vitamin E. In spite of the paper by Moore, Sharman \& Ward (I957), there is no evidence for this belief. In baking, 50\% of the vitamin $\mathrm{E}$ in the flour is destroyed and cereals do not contribute much vitamin $\mathrm{E}$ to the diet (see Frazer, Hickman, Sammons \& Sharratt, 1956). We indeed know little of the daily requirements of vitamin $\mathrm{E}$.

If we are to take a broad and fair view after examination of all the established facts, I find it extremely difficult to believe, as I have always done, that there is any valid criticism of the procedure of pleasing the public by giving them the white flour they desire, provided that fortification as we understand it today is properly carried out. There is quite frankly no evidence that a normal diet containing bread made from enriched flour lacks any essential nutrient as opposed to a similar diet in which the bread is made from flour of longer extraction, for example $80-85 \%$. The evidence is that the diet will not be lacking in the rarer components of the $B$ group of vitamins such as pantothenic acid, pyridoxine, folic acid or biotin. The fact remains that no evidence of malnutrition has been shown in all the many carefully conducted tests so far made.

\section{REFERENCES}

Frazer, A. C., Hickman, J. R., Sammons, H. G. \& Sharratt, M. (1956). F. Sci. Fd Agric. 7, 375. Great Britain. Parliament (1945). Report of the Conference on the Post-War Loaf. [Cmd.6701]. London: H.M. Stationery Office.

Great Britain. Parliament (1956). Report of the Panel on Compasition and Nutritive Value of Flour [Cmd. 9757]. London: H.M. Stationery Office.

Kent-Jones, D. W. (1946). Proc. Nutr. Soc. 4, I4.

Kent-Jones, D. W. (1949-50). F. R. Soc. Arts, 98, ז 50.

McCance, R. A. \& Widdowson, E. M. (1956). Breads White and Brown. London: Pitman Medical Publishing Co. Ltd.

Moore, T., Sharman, I. M. \& Ward, R. J. (1957). F. Sci. Fd Agric. 8, 97.

Widdowson, E. M. \& McCance, R. A. (1954). Spec. Rep. Ser. med. Res. Coun., Lond., no. 287.

Wilder, R. M. (1949). Canad. med. Ass. F. 60, 329.

Wilder, R. M. (1956). F. Amer, med. Ass. r62, I539.

\section{Analytical problems in the determination and control of extraction rates of flour}

By J. R. Nicholls and J. R. Fraser, Department of the Government Chemist, Government Laboratory, Clement's Inn Passage, Strand, London, W.C.2

Extraction rate is a term used to define the grade of a flour and is expressed as a percentage showing the relation of the weight of flour to the weight of wheat from which it is obtained. It is inherent in the term that it applies only to flour produced and not to any other product separated from wheat. Flour is, however, a generic term covering a wide variety of products and it must be interpreted, for the purposes of definition of extraction rate, as the product which the miller sets out to prepare 